\title{
ÁREAS DE PROTEÇÃO AMBIENTAL COMO FERRAMENTAS PARA GESTÃO DE ESPAÇOS DE INTERESSE DO TURISMO NO ESTADO DO RIO DE JANEIRO: PROPOSTA DE ESTRATÉGIA PARA IMPLEMENTAÇÃO.
}

\author{
Paulo Bidegain ${ }^{1}$
}

\section{RESUMO}

O Governo do Estado do Rio de Janeiro, através do Instituto Estadual do Ambiente (INEA), gerencia um total de 11 Áreas de Proteção Ambiental (APAs), estabelecidas entre 1984 e 2007. As APAs derivam de decisões isoladas, quase sempre configurando uma resposta para proteger um espaço ameaçado pelo crescimento urbano ou por determinado empreendimento, sem atender um planejamento global de conservaça ambiental do território do Estado. Apesar da importância das APAs, históricamente elas sempre ocuparam um patamar secundário nas prioridades dos órgãos ambientais estaduais. Decorridos 30 anos de experiência com APAs (1984-2015), a gestão permanece em estágio rudimentar e sem um rumo claro. Tendo em vista que as APAs constituem valiosas ferramentas para gestão de espaços onde o turismo é intenso ou tem grande potencial, é proposta uma estratégia visando o fortalecimento das APAs não só para o objetivo supramencionado, mas para promover a conservação ambiental geral dos espaços, requisito fundamental para o desenvolvimento do turismo. A gestão de Áreas de Proteção Ambiental - APAs clama pelo estabelecimento de uma política específica para guiar a implantação e a operação, tirando-as do plano secundário em que sempre estiveram. As APAs necessitam de definições e procedimentos gerenciais mais claros sobre para que servem, como devem ser planejadas, implantadas e operadas, qual é a infra-estrutura administrativa mínima que deve conter e como deve ser o plano de manejo, para que possam de fato contribuir para o desenvolvimento.

Palavras chave: Áreas de Proteção Ambiental (APAs); planejamento; turismo; Rio de Janeiro.

\begin{abstract}
Área de Proteção Ambiental or APA (Environmental Protected Area) is a Brazil's protected area category corresponding to IUCN's system Type V - Protected Landscape or Seascape (IUCN, 2013). Considering that APAs are significant tolls to protect territories for tourism development, a strategy is proposed to strength the State of Rio de Janeiro Environmental Protected Areas.
\end{abstract}

Keywords: Environmental Protected Area (EPA); planning; tourism, Rio de Janeiro.

\section{INTRODUÇÃO}

Áreas de Proteção Ambiental (APA) são definidas como:

"Área em geral extensa, com um certo grau de ocupação humana, dotada de atributos abióticos, bióticos, estéticos ou culturais especialmente importantes para a qualidade de vida e o bem-estar das

\footnotetext{
1 BSP Consultoria e Treinamento - Biólogo especialista em Parques e Áreas Protegidas e Conservação Ambiental - E-mail: pp_bidegain@ hotmail.com
} 
populações humanas, e tem como objetivos básicos proteger a diversidade biológica, disciplinar o processo de ocupação e assegurar a sustentabilidade do uso dos recursos naturais" (art. 15 da Lei no 9.985/00).

O Governo do Estado do Rio de Janeiro, através do Instituto Estadual do Ambiente (INEA), gerencia um total de 11 APAs, estabelecidas entre 1984 e 2007, a saber: Maricá (1984), Tamoios (1986), Massambaba (1986), Mangaratiba (1987), Serra de Sapiatiba (1990), Macaé de Cima (2001), Pau-Brasil (2002), Bacia do Rio Macacu (2002), Sepetiba II (2004), Gericinó-Mendanha (2005) e Rio Guandu (2007). Em 2013, a Lei $n^{\circ} 6.573$ extinguiu as APAs dos Frades (1990) e da Floresta de Jacarandá (1985), posto que o Parque Estadual dos Três Picos incorporou os melhores remanescentes florestais de ambas.

As APAs derivam de decisões isoladas, pois nunca houve um planejamento do sistema de áreas protegidas cobrindo o território do Estado para orientar as ações. As iniciativas foram tomadas quase sempre como uma resposta para proteger um espaço ameaçado pelo crescimento urbano devido à inação das prefeituras ou por determinado empreendimento. Uma delas, Sepetiba II, foi criada por imposição do Ministério Público.

Apesar da importância das APAs, esta categoria ocupa um patamar secundário nas prioridades dos órgãos ambientais estaduais, sempre focados na gestão e implantação dos parques, reservas biológicas e estações ecológicas. Decorridos 30 anos de experiência com APAs (1984-2015), a gestão permanece em estágio rudimentar, sendo guiada unicamente pelos Planos de Manejo. Só recentemente foi editado pelo INEA o Roteiro Metodológico para elaboração de Planos de Manejo de APAs (2014).

Inexistem estratégias, planos ou programas globais para guiar a implantação, avaliações de custo operacional, análises de efetividade ou mesmo manuais tratando dos procedimentos operacionais gerais. Em resumo, não há um direcionamento corporativo estabelecendo como as APAs devem ser gerenciadas e as suas prioridades. A gestão é como uma nau que parte de um porto sem ter um destino definido. Sem uma rota traçada, fica ao sabor do vento, as provisões acabam, a tripulação morre e o navio fica a deriva.

Na prática, a diferença de um território que é APA de outro que não é resume-se ao zoneamento, administrador, conselho e mais uma parada no curso dos processos administrativos. Quase sem estrutura e com orçamento beirando o zero, o gestor de uma APA tem poucas condições de promover articulações, impor o zoneamento ou mesmo implementar programas e projetos.

Tendo em vista que as APAs constituem valiosas ferramentas para gestão de espaços onde o turismo é intenso ou tem grande potencial no Estado do Rio de Janeiro, propõe-se neste artigo uma estratégia visando o fortalecimento das APAs não só para o propósito supramencionado, mas para a conservação ambiental geral dos espaços, requisito fundamental para o desenvolvimento do turismo.

\section{MÉTODOS}


Para elaboração da estratégia foram analisadas as legislações federal e estadual referentes às unidades de conservação bem como o estado atual do conjunto de APAs Estaduais, além da literatura técnica, em especial as publicações da International Union for Conservation of Nature (IUCN). Cabe assinalar que as APAs estaduais são pobremente documentadas, inexistindo relatórios analíticos ou de avaliação de efetividade.

\section{RESULTADOS}

É proposto que o órgão ambiental formule uma "Estratégia para Fortalecimento das Áreas de Proteção Ambiental" para guiar a gestão pelos próximos dez anos, submetendo a minuta à consulta pública, aos municípios e aos segmentos do turismo e, em sequência, ao Conselho Estadual do Meio Ambiente (CONEMA) para aprovação final. Apresenta-se a seguir de forma sucinta, alguns elementos a serem considerados na referida estratégia.

\section{Base Legal e Definição}

A categoria APA foi instituída em 1981 pela Lei Federal nº 6.902, que criou também as Estações Ecológicas. No sistema internacional da IUCN, APA equivale a categoria V Protected Landscapes / Seascapes. Definições e regras gerais sobre APAs são encontradas nos seguintes atos legais: i) Constituição Federal, artigo 225, § $1^{\circ}$, inciso III; ii) Lei ${ }^{\circ} 6.902$ de 27 de Abril de 1981, que dispõe sobre a criação de Estações Ecológicas, Áreas de Proteção Ambiental e dá outras providências; iii) Resolução CONAMA nº 10, de 14 de dezembro de 1988, que dispõe sobre a regulamentação das Áreas de Proteção Ambiental - APAs, e; iv) Lei Federal no 9.985, de 18 de julho de 2000, que instituiu o Sistema Nacional de Unidades de Conservação e seus regulamentos, em especial os Decretos $n^{\circ} 4.340$, de 22 de agosto de 2002 e $\mathrm{n}^{\circ}$ 6.848, de 14 de maio de 2009 (altera e acrescenta dispositivos ao Decreto no 4.340, de 22 de agosto de 2002, para regulamentar a compensação ambiental).

O artigo 46 do Decreto Federal $n^{\circ} 4.340$, de 22 de agosto de 2002 determinou que cada categoria de unidade de conservação integrante do SNUC fosse objeto de regulamento específico. Todavia, nenhum regulamento moderno específico sobre APA foi baixado pelo Governo Federal. O documento "Planejamento e gestão de APAs: enfoque institucional", publicado pelo IBAMA em 1997 é a única tentativa oficial de estabelecer diretrizes gerenciais para a categoria. Além de defasado, o documento é muito mais analítico do que prático.

A estratégia deve sinalizar a necessidade de regulamento estadual específico sobre APA, para aclarar diversos pontos importantes.

\section{Visão de Futuro}

A Estratégia deve estabelecer uma visão de futuro do conjunto de APAs, examinando aquelas que devem permanecer como são hoje, as que podem ser ampliadas ou extintas e os espaços naturais que demandam, por diversos motivos, a criação de novas APAs. Cabe assinalar que diversos países têm criado áreas protegidas marinhas (conhecidas mundialmente como MPA - Marine Protected Areas), empregando categorias semelhantes às APAs. No 
(a)

Brasil, o Estado de São Paulo seguiu a tendência e criou três APAS Marinhas (Litoral Norte, Litoral Centro e Litoral Sul). Ao lado das Reservas Extrativistas, Reservas de Desenvolvimento Sustentável e Refúgios da Vida Silvestre, as APAs são valiosas ferramentas para gestão de espaços aquáticos (marinhos, lacustres, lagunas e fluviais).

A conversão das principais baías, lagunas e lagoas em APAs traz inúmeras vantagens para a conservação ambiental, a gestão dos usos múltiplos, dentre eles o turismo, a geração de empregos e renda e a produção de receitas para sustentar o custeio. Cabe mencionar que a IUCN editou um guia de melhores práticas para áreas protegidas marinhas, importante de ser avaliado (IUCN, 2002b).

Dentre as vantagens menciona-se: i) os ecossistemas passam a ter gestores com dedicação exclusiva, capazes de mobilizar as partes interessadas e promover parcerias; ii) possibilidade de aplicação de zoneamentos tridimencionais dos usos múltiplos, amplamente negociados, reduzindo conflitos e impactos ambientais adversos, favorecendo assim os usos sustentáveis, iii) acesso aos recursos do Fundo da Mata Atlântica para financiamento da elaboração dos Planos de Manejo; e iv) incorporação das APAs de lagoas e lagunas ao sistema estadual de recursos hídricos, garantindo acesso aos recursos do Fundo Estadual de Recursos Hídricos tanto para investimentos quanto para apoio operacional através de parcerias com as Entidades Delegatárias. Além disso, como os ecossistemas aquáticos têm intenso uso turístico-recreativo, abre-se a possibilidade de acessar fundos federais e estaduais para desenvolver programas e implantar infraestrutura para fomentar a atividade no interior das APAs.

O cenário futuro aqui proposto é constituído por 12 APAs:

- $\quad$ APA do Rio Guandu;

- $\quad$ APA de Macaé de Cima;

- $\quad$ APA do Rio Macacú;

- $\quad$ APA da Região dos Lagos;

- $\quad$ APA do Ecossistema Lagunar de Maricá;

- $\quad$ APA dos Ecossistemas Lagunares de Saquarema e Jaconé;

- $\quad$ APA dos Ecossistemas Lagunar de Araruama;

- $\quad$ APA do Ecossistema das Lagoas Feia e de Cima;

- $\quad$ APA do Ecossistema Fluvial do Baixo Paraíba do Sul;

- $\quad$ APA da Baia de Sepetiba;

- $\quad$ APA da Baia de Ilha Grande;

- $\quad$ APA da Baia de Guanabara; 
Para atingir o cenário projetado, será necessário extinguir a APA Gericó-Mendanha, pois o Parque Estadual do Mendanha foi estabelecido, e municipalizar a APA de Sepetiba II. Seguem comentários sucintos sobre as APAs.

\section{APA do Rio Guandu e de Macaé de Cima}

Estas APAs permanecem sem alteração de limites e denominação. Os rios Guandu e Macaé de Cima podem ser transformados em Parques Fluviais administrados pelos Gestores das APAs, em parceria com Prefeituras ou através de concessão. A sede da APA de Macaé de Cima deve ser remodelada para incluir posto de informações ao turista.

\section{$\underline{\text { APA do Rio Macacú }}$}

Ampliada para abranger não somente os rios, mas a parte superior da bacia hidrográfica do rio Macacu, na linha das "Áreas de Proteção aos Mananciais" utilizadas no Estado de São Paulo. O Macacu é o rio em melhor estado da Bacia Hidrográfica da Baia de Guanabara, tendo excelente potencial turístico. Pode ser transformado em Parque Fluvial administrado pelo Gestor da APA com parceriais. A sede pode ser remodelada para incluir um posto de informações ao turista.

\section{$\underline{\text { APA da Região dos Lagos }}$}

Criada a partir da fusão das APAs de Sapiatiba, Pau-Brasil e Massambaba, tendo em vista que o Parque Estadual da Costa do Sol absorveu grande parte da superfície e as paisagens mais significantes. Como não há alterações de limites, apenas de nome, pode ser feito por Decreto. Sede nas dependências da Superintendência Regional.

\section{APA do Ecossistema Lagunar de Maricá}

Criada a partir da ampliação da APA Maricá, com alteração de nome. Compreende o Sistema Lagunar de Maricá (lagoas de Maricá propriamente dita, Barra, Padre e Guarapina, pelos canais do Corderinho e da Ponta Negra e pelas margens, brejos periféricos e pela superficie da atual APA Maricá. Trata-se da maior laguna da Região Metropolitana, sendo ameaçada pelo crescimento urbano da cidade de Maricá. Excelente potencial turístico para geração de emprego e renda. Demanda planejamento de um conjunto de parques municipais e praças ao longo das margens para garantir definitivamente o acesso público, evitar invasões e proteger habitats de grande importância, além da belíssima paisagem. A sede, com espaço para funcionar como Centro de Visitantes, pode ser implantada na margem.

\section{$\underline{\text { APA dos Ecossistemas Lagunares de Saquarema e Jaconé }}$}

Abrangendo a superfície das lagunas no seu nivel máximo normal acrescido de uma faixa ao longo das margens incorporando brejos e outros elementos, além do canal Salgado que une as lagunas de Saquarema e Jaconé. Grande potencial para turismo e recreação 
aquática. Também demanda o planejamento de um conjunto de parques municipais e praças ao longo das margens, com os mesmos propósitos anteriomente citados. A sede, com espaço para funcionar como Centro de Visitantes, pode ser implantada na margem.

\section{$\underline{\text { APA do Ecossistema Lagunar de Araruama }}$}

Compreendendo integralmente a lagoa de Araruama, o canal de Itajuru e suas margens em largura variável, excetuando os espaços que fazem parte do Parque Estadual da Costa do Sol (PECS) e as margens urbanizadas ao longo do canal de Itajuru. A laguna de Araruama é historicamente uma dos maiores atrações turísticas da Região dos Lagos e vem sendo recuperada gradativamente. Demanda o planejamento de um conjunto de parques municipais e praças ao longo das margens, com os mesmo propósitos anteriomente citados. A sede, com espaço para funcionar como Centro de Visitantes, pode ser implantada na margem. Trata-se de uma APA estratégica devido ao elevado potencial recreativo e a necessidade de gerenciamento dos usos múltiplos.

\section{$\underline{\text { APA do Ecossistema das Lagoas Feia e de Cima }}$}

Compreendendo a Lagoa de Cima, o canal que as une, as lagoas Feia, Ribeira e do Luciano e o canal da Flechas. Os limites da APA devem ser estradas ou outros marcos físicos. Os limites dos terrenos públicos (terrenos marginais) no entorno da Lagoa Feia devem ser fixados tendo como limite externo a cota de 4,73m, que corresponde ao nível máximo antigo da água, de acordo com dados do DNOS apresentados no estudo "Saneamento das Várzeas nas Margens do Rio Paraíba do Sul a Jusante de São Fidélis”, publicado em 1969. Trata-se de uma das lagoas mais importantes do Estado do Rio de Janeiro, há décadas abandonada. Tem grande potencial para usos múltiplos, incluindo turismo. A sede, com espaço para funcionar como Centro de Visitantes pode ser implantada na margem, na vila de Ponta Grossa dos Fidalgos. A conversão em APA promoverá o resgate de sua importância histórica e ambiental, tirando-a do limbo em que se encontra.

\section{$\underline{\text { APA do Ecossistema Fluvial do Baixo Paraíba do Sul }}$}

Abarcando o canal do rio Paraíba do Sul no trecho entre a foz e um ponto a jusante da cidade de Campos, além das margens e a integridade dos manguezais na foz. O segmento fluvial tem belos cenários, com diversas ilhas, destacando-se os manguezais e um canal francamente navegável para embarcações de passeio, além de biodiversidade considerével por ser um ecossistema de água doce e estuarino. Elevado potencial turístico subaproveitado. Por ser um rio federal, a criação desta APA abre oportunidades de acesso a recursos federais e parcerias com IBAMA e ANA. Vale ressaltar que o Estado do Ceará tem diversas APAs estuarinas (rios Curu, Mundaú e Ceará). O ICMBIO gerencia a APA da Foz do São Francisco.

$\underline{\text { APA da Baia de Sepetiba }}$ 
Abrange a Baia de Sepetiba e suas ilhas e margens, incluindo todos os manguezais e praias e parte dos costões rochosos ao longo da margem continental, sendo delimitada por estradas ou outros marcos físicos. A criação desta APA, proposta em 1998, é uma ação decisiva para por um fim na gestão ambiental acéfala, reduzir os conflitos e a velocidade da degradação da águas, fundos, ilhas e manguezais e traçar um rumo para o futuro, com a participação de todos os usuários e parceiros. Seu potencial turístico e pesqueiro é enorme, mas o uso industrial tem se fortalecido além do desejável, podendo eliminar empregos nos outros setores. O melhor local para sede é Itacurussá. Bidegain (2012b) analisa em detalhe as vantagens de criação desta APA.

\section{APA da Baia de Ilha Grande}

Cobrindo integralmente a Baia de Ilha Grande e suas margens, incluindo todos os manguezais e praias, ilhas e parte dos costões rochosos (até certa altura), excluindo as ilhas que fazem parte da APA de Cairuçu e da Estação Ecológica de Tamoios. Criada a partir da ampliação da APA Tamoios com alteração de nome. Bidegain (2012c) avalia com mais detalhes diversas justificativas para criação desta APA e seus desafios.

\section{$\underline{\text { APA da Baia de Guanabara }}$}

Cobrindo integralmente as praias, os mangues, costões rochosos e a baia propriamente dita, excluindo-se as superfícies da APA de Guapi-Mirim e das Ilhas do Governador e Paquetá (estas apenas o litoral). Em muitos trechos os limites serão ruas como em Icaraí (Niterói) ou estritamente o litoral, como no Aterro do Flamengo. Deve-se evitar ao máximo avançar os limites sobre áreas urbanizadas. O importante é o litoral e a espaço marinho.

Trata-se de uma APA estratégica para possibilitar o gerenciamento dos usos múltiplos. O Conselho desta APA pode reunir instituições e empresas de grande importância, que podem colaborar com a gestão operacional e a recuperação do cartão postal do Brasil. Ao ganhar um Administrador, a Baía de Guanabara dará um salto para melhorar sua capacidade de gestão. A Ilha de Brocoió, propriedade subutilizada do Estado, poderia ser incoporada ao INEA para uso turistico através de concessão.

\section{Vinculação Administrativa}

O melhor arranjo institucional para as APAs é posicioná-las nas Superintendências Regionais do INEA, favorecendo tanto as Superintendências quanto as APAs. Afinal, o gestor de uma APA não deixa de ser um superintendente de uma área geográfica menor. O gestor da APA passa a ter dupla subordinação. Ao Superintendente na parte operacional do dia-a-dia. Ao Diretor de Áreas Protegidas nos assuntos relacionados ao plano de manejo e questões técnicas de maior âmbito. O "modus-operandi" pode ser estabelecido em protocolo operacional corporativo. O gestor da APA passa contar com apoio de recursos humanos, equipamentos e materiais da Superintendência para prestar seus serviços, liberando-se para atividades de articulação, mobilização e busca de projetos, ao invés de ser tragado pelo licenciamento e fiscalização. 


\section{Planificação}

Após aprovação da Estratégia, documento sucinto de direcionamento geral, é necessário elaborar um Plano de Investimentos Plurianual das APAs, visando implementar as diretrizes e rumos definidas na Estratégia no longo prazo, através de ações, programas e projetos, todos com metas, atividades, custo estimado e fontes de recursos. No bojo do processo de elaboração do Plano, é recomendável que seja contratado um estudo global para implementar a visão, tendo como produtos os estudos técnicos com as minutas de decreto e o memorial de limites para criação das novas APAs. Quanto aos Planos de Manejo é preciso ainda avaliar o custo dos produtos a serem contratados com base no novo roteiro metodológico. Caso eles sigam a tendência dos planos de manejo do Estado, o valor ultrapassará os R 10 milhões, tendo em vista que são 12 APAs, o que configuraria um absurdo.

Os Zoneamentos da APAs devem estar alinhados ao zoneamento ecológico-econômico do Estado e, quando possivel aos zoneamentos municipais. Recomenda-se que os Planos de Manejo indiquem a criação de Refúgios da Vida Silvestre para proteção mais rígida de habitats especiais no interior de uma APA, como cavernas, lagoas pequenas, brejos, fragmentos florestais, morros isolados com beleza cênica, ilhas sem ocupação e outros.

\section{Manual de Operação}

A Estratégia deve prever a produção de Manual de Operação das Áreas de Proteção Ambiental contendo os procedimentos gerenciais relacionados a finanças; governança e modelo de gestão; recursos humanos; conhecimento, monitoramento e pesquisa; turismo, educação ambiental; infraestrutura, trilhas e sinalização; logística, equipamentos e materiais; conservação ambiental e usos dos recursos naturas, patrimônio histórico - cultural, proteção e condutas em situações de emergência, comunicação e promoção e inserção regional além de outros.

\section{Finanças}

O Parágrafo Único do art. 33 do Decreto no 4.340/2002 cita que no caso de Área de Proteção Ambiental, os recursos da compensação somente poderão ser aplicados para custear as seguintes atividades: i) elaboração do Plano de Manejo; ii) atividades de proteção da unidade; iii) realização das pesquisas necessárias para o manejo da unidade, sendo vedada a aquisição de bens e equipamentos permanentes; iv) implantação de programas de educação ambiental; e v) financiamento de estudos de viabilidade econômica para uso sustentável dos recursos naturais da unidade afetada.

As APAs podem possuir um Plano de Investimento Plurianual, contendo os projetos a serem implementados em cinco anos, selecionados a partir dos Planos de Manejo ou mesmo aqueles que se aplicam a todos. Cada APA deve ter um orçamento individual, tarefa gerencial tão primária que não cabe aqui comentar sua relevância. Afinal como planejar e operar sem saber quanto custa? Orçamentos operacionais das APAs podem ser integrados ao orçamento das Superintendências. Não faz sentido dotar todas as APAs com equipe completa, veículos, equipamentos, sede e outros requisitos tendo o INEA adotado o modelo de gestão de território através das Superintendências e Regiões Hidrográficas. 


\section{Parcerias}

É fundamental que as APAs sejam administradas a partir de Termos de Cooperação com a(s) Prefeitura(s), por mais penoso que o processo possa aparentemente ser, para harmonizar procedimentos e condutas. O Conselho da APA é o fórum privilegiado para expor e discutir os conflitos e os termos de parceria. Parcerias com a EMATER são também fundamentais. Sugere-se que seja estimulada a criação de associações tipo "Amigos da APA" para captar recursos e contribuir na gestão e nos investimentos, para que as pessoas possam ter um papel mais ativo.

\section{Turismo}

APAs podem ser planejadas como destinos turísticos, adaptando-se as ferramentas do setor, sendo os estudos elegíveis para financiamento através de recursos de compensação ambiental. Recomendando-se observar as diretrizes da IUCN (2002 c) e ainda incorporar os distintos segmentos do turismo nos Conselhos, como transporte, alimentação, hospedagem, proprietários de atrações e RPPNs, agências e operativos e da mídia e secretarias de turismo.

\section{Infra-Estrutura, Veículos e Equipamentos}

Posto que a Lei do SNUC não permite aplicação de recursos ambientais de compensação ambiental para infra-estrutura e compra de equipamentos, pode-se utilizar os recursos do Fundo Estadual de Recursos Hídricos (FUNDRHI) para estas finalidades, naquelas APAs de lagoas, lagunas e de trechos de rios. Para as demais é necessário empregar recursos do próprio INEA.

As sedes das APAs podem ser prioritariamente instaladas nas sedes das Superintendências Regionais.

\section{Proteção}

Atividades de proteção envolvem inevitavelmente recursos humanos, cuja contratação não é financiada pela Lei do SNUC e seu regulamento, pois trata-se de custeio. Esta Lei, por outro lado, permite o emprego de recursos em "atividades de proteção da unidade", permitindo, por exemplo, a contratação de serviços de operaçao de drone para patrulhamento aéreo das APAs, cujo custo é muito inferior ao de helicóptero.

\section{Comunicação e Divulgação}

É recomendável formular um Programa de Comunicação e Divulgação das APAs para guiar a atividade. Como primeiro passo, sugere-se produzir um Portal das APAs, tendo cada uma um site específico linkado, todos eles seguindo modelos de sites de turismo, como por exemplo o de Itacaré (http://www.itacare.com.br/).

\section{CONCLUSÃO}

O potencial do turismo nas APAs do Estado do Rio de Janeiro é excepcional, mas depende de um novo modelo de gestão ancorado em uma estratégia clara e factível, produzida 
de forma participativa e aprovada pelo Conselho Estadual do Meio Ambiente. Somente assim será possivel gerar emprego e renda e retirar as APAs do plano secundário em que sempre estiveram, valorizando-as.

\section{REFERENCIAS}

BIDEGAIN, P. Importância das APAs Marinhas e Lagunares (2012a). Disponível em: http://parquespark.blogspot.com.br/2012/02/o-desafio-das-apas-no-estado-do-riode 1713.html.

BIDEGAIN, P. APA do Ecossistema Marinho da Baia de Sepetiba (2012b). Disponível em: http://parquespark.blogspot.com.br/2012/02/o-desafio-das-apas-no-estado-do-rio-de_27.html

BIDEGAIN, P. A APA Marinha da Baia de Ilha Grande (2012c). Disponível em https://bay174.mail.live.com/?tid=cmUWtHlc3G5BGfpgAiZMF9UA2\&fid=flinbox

INEA. Blog das APAs. Disponível em: http://geusoinearj.blogspot.com.br/. Acessado em 08/05/2015.

INEA. Roteiro Metodológico para elaboração de Planos de Manejo: Áreas de Proteção Ambiental. Rio de Janeiro, Instituto Estadual do Ambiente, 2014, 64.

IUCN. Guidelines for Applying Protected Area Management Categories. Gland, Switzerland, 2013. 86p.

IUCN. Management Guidelines for IUCN Category V Protected Areas: Protected Landscapes/Seascapes. Best Practice Protected Area Guidelines Series No. 9. Gland and Cambridge, 2002a

IUCN. Guidelines for Marine Protected Areas. Best Practice Protected Area Guidelines. Series No. 3. Gland and Cambridge, 2002b.

IUCN. Sustainable Tourism in Protected Areas, Guidelines for Planning and Management. World Commission on Protected Areas, 2002c.

SMA. Secretaria do Meio Ambiente. Fundação Florestal. Apas Marinhas. Disponível em: http://fflorestal.sp.gov.br/unidades-de-conservacao/apas-marinhas/. Acessado em 08/05/2015. 